\title{
Divergência genética em cultivares de morangueiro, baseada em caracteres morfoagronômicos ${ }^{1}$
}

\author{
Rafael Gustavo Ferreira Morales ${ }^{2}$, Juliano Tadeu Vilela de Resende ${ }^{3}$, Marcos Ventura Faria ${ }^{3}$, Paulo Roberto da \\ Silva ${ }^{4}$, Alex Sandro Torre Figueiredo ${ }^{5}$, Rafaela Carminatti ${ }^{6}$
}

\section{RESUMO}

Os caracteres morfoagronômicos são tradicionalmente usados na caracterização de cultivares e no estudo da divergência genética, contribuindo na definição de estratégias para o melhoramento genético. Este trabalho teve por objetivo avaliar a divergência genética por meio de caracteres morfoagronômicos de 11 cultivares de morangueiro (Aromas, Camarosa, Camino Real, Campinas, Diamante, Dover, Oso Grande, Sweet Charlie, Toyonoka, Tudla e Ventana), nas condições climáticas da região Centro-Sul do Paraná. Foram analisados 29 caracteres morfoagronômicos relacionados com a planta, folha, flor, fruto e aquênios do morangueiro. As similaridades genéticas foram calculadas por meio de análise multivariada e, os cultivares, agrupados com base na matriz de similaridade genética, usando-se UPGMA. Dentre os 29 caracteres morfoagronômicos avaliados, oito apresentaram diferenças não significativas ( $\mathrm{p} \leq 0,05)$. A similaridade média foi de 38\%, variando de 19 (aromas e camino real) a 62\% (Camino Real e Camarosa; Aromas e Sweet Charlie). O dendrograma alocou os cultivares em quatro grupos, contudo, essa divisão não foi coerente com a origem e genealogia dos cultivares. O cultivar Tudla apresenta elevado potencial "per se" para utilização em programas de melhoramento. O cruzamento mais promissor com base nos caracteres morfoagronômicos é entre os cultivares Camarosa e Campinas.

Palavras-chave: Fragaria x ananassa Duch., melhoramento de plantas, similaridade, análise multivariada.

\section{ABSTRACT}

\section{Genetic diversity in strawberry cultivars based on morphological characteristics}

Morphological characteristics are traditionally used to characterize cultivars, contributing to the development of strategies for genetic improvement. In this study we evaluated the genetic diversity using morphological characteristics of 11 strawberry cultivars (Aromas, Camarosa, Camino Real, Campinas, Diamante, Dover, Oso Grande, Sweet Charlie, Toyonoka, Tudla and Ventana) in the south-central region of Paraná. A total of 29 strawberry morphological characteristics related to plant, leaf, flower, fruit and achenes were analyzed. Genetic similarities were calculated by multivariate analysis and cultivar grouping was based on a genetic similarity matrix using UPGMA. Among the 29 morphological characters evaluated, eight showed non-significant differences $(\mathrm{p}<0.05)$. The average similarity was $38 \%$, ranging from 19\% (Aromas and Camino Real) to 62\% (Camino Real and Camarosa, Aromas and Sweet Charlie).

\footnotetext{
Recebido para publicação em maio de 2010 e aprovado em abril de 2011

' Parte da dissertação de mestrado apresentada ao Curso de Pós-Graduação em Fitotecnia da Universidade Estadual do Centro-Oeste (Unicentro), para obtenção do grau de Mestre em Fitotecnia

${ }^{2}$ Engenheiro-Agrônomo, Mestre. Departamento de Agronomia, Universidade Federal de Lavras, 37200-000, Lavras, Minas Gerais, Brasil. moralescefet@yahoo.com.br

${ }^{3}$ Engenheiro-Agrônomo, Doutor. Departamento de Agronomia, Universidade Estadual do Centro-Oeste, Campus Universitário CEDETEG, Caixa Postal 3010, 85040-080, Guarapuava, Paraná,Brasil.jresende@unicentro.br; mfaria@unicentro.br

${ }^{4}$ Biólogo, Doutor. Departamento de Biologia, Universidade Estadual do Centro-Oeste (UNICENTRO), Rua Salvatore Renna-Padre Salvador, 875, Santa Cruz, 85015-430, Guarapuava, Paraná, Brasil. pabloprs@ hotmail.com

${ }^{5}$ Acadêmico do curso de agronomia. Universidade Estadual do Centro-Oeste (UNICENTRO). Rua Salvatore Renna-Padre Salvador, 875, Santa Cruz, 85015-430, Guarapuava, Paraná, Brasil. alexfiqueiredo@ hotmail.com

${ }^{6}$ Nutricionista. Departamento de nutrição. Universidade Estadual do Centro-Oeste (UNICENTRO). Rua Salvatore Renna-Padre Salvador, 875, Santa Cruz, 85015-430, Guarapuava, Paraná, Brasil. rafa_cmt@hotmail.com
} 
The dendrogram separated the cultivars into four groups, however, this grouping was not consistent with the origin and genealogy of the cultivars. The cultivar Tudla has a high potential "per se" for use in breeding programs. The most promising crossing, on the basis of morphological characteristics, is between cultivars Camarosa and Campinas.

Key words: Fragaria $\mathrm{x}$ ananassa Duch., multivariate analysis, plant breeding, similarity.

\section{INTRODUÇÃO}

Conhecer as relações genéticas, entre os genótipos disponíveis para um programa de melhoramento genético, é fundamental para a definição das estratégias de utilização do germoplasma de forma eficiente (Gichuki et al., 2003). Para os melhoristas, a distinção da relação genética entre os genótipos está relacionada com a informação fenotípica da planta (Klocke et al., 2002). Muitos métodos estão disponíveis para avaliar a divergência genética em populações de plantas, diferenciandose na habilidade em detectar diferenças entre genótipos, custos, facilidade de uso, consistência e repetibilidade dos resultados (Milach, 1998).

A utilização de caracteres morfoagronômicos na avaliação da divergência genética proporciona uma simplificação da quantificação da variação genética e, simultaneamente, possibilita avaliar o desempenho dos genótipos no ambiente de crescimento (Fufa et al., 2005). De forma geral, os caracteres morfoagronômicos são eficientes para estudo de divergência genética. Porém, é importante que sejam selecionados os caracteres adequados, como relatam Chahidi et al. (2008) que demonstraram ser ineficiente o uso de caracteres relacionados com a planta e a folha no estudo de divergência genética da tangerina (Citrus reticulata), sendo os caracteres de fruto mais informativos e úteis nesse caso.

No morangueiro, os principais caracteres morfoagronômicos levados em consideração na identificação e caracterização de cultivares, são descritos por Faedi et al. (2009). Como exemplo de caracteres morfológicos, podese citar a forma do recorte da dentição foliar, a pigmentação da estípula, o tamanho da corola em relação ao cálice floral e o formato do fruto e, como exemplo de caracteres agronômicos, a produção de frutos, a massa média de frutos, a época de floração e a posição da inflorescência na folhagem. Conti et al. (2002) estudaram a divergência genética entre cinco cultivares de morangueiro, utilizando caracteres morfológicos e marcadores RAPD, e verificaram agrupamento muito similar dos cultivares, a partir dessas duas fontes de informação, observando, apenas, variação no grau de similaridade entre os cultivares.
Estimativas da divergência genética do germoplasma disponível, obtidas a partir de caracteres morfoagronômicos, fazem parte das primeiras etapas do estabelecimento de um programa de conservação ou melhoramento genético. Portanto, a divergência entre cultivares de morangueiro será útil para o estabelecimento de um programa de melhoramento genético da espécie. O objetivo deste estudo foi avaliar a divergência genética entre cultivares de morangueiro, por meio de caracteres morfoagronômicos, nas condições climáticas da região Centro-Sul do Paraná.

\section{MATERIAL E MÉTODOS}

O experimento foi realizado no Setor de Olericultura da Universidade Estadual do Centro-Oeste (UNICENTRO), situada em Guarapuava, Centro-Sul do Paraná. O clima da região de cultivo é classificado como $\mathrm{Cfb}$ (Subtropical mesotérmico úmido), sem estação seca, com verões frescos e inverno moderado, conforme a classificação de Koppen. A temperatura média mínima anual é $12,7^{\circ} \mathrm{C}$, temperatura média máxima anual de $23,5^{\circ} \mathrm{C}$, umidade relativa do ar de $77,9 \%$, altitude de, aproximadamente, $1100 \mathrm{~m}$ e precipitação média anual de $1944 \mathrm{~mm}$ (Thomaz \& Vestena, 2003).

O experimento foi conduzido em blocos casualizados, com quatro repetições, sendo os tratamentos constituídos de 11 cultivares: Aromas, Camarosa, Camino Real, Campinas, Diamante, Dover, Oso Grande, Sweet Charlie, Toyonoka, Tudla e Ventana. Cada tratamento foi composto por três vasos, com espaçamento de $30 \mathrm{~cm}$ entre vasos e $1 \mathrm{~m}$ entre blocos, totalizando 33 vasos por bloco, dispostos numa única linha.

As matrizes dos cultivares foram obtidas na empresa Multiplanta Biotecnologia Vegetal Ltda. e multiplicadas em viveiro. As mudas receberam "toaletes", em que foram retiradas folhas velhas, secas e com sintomas de doença, além de terem as raízes aparadas, remanescendo $10 \mathrm{~cm}$. Após a toalete, as raízes foram imersas por 15 minutos em calda bordalesa, na concentração de $4 \mathrm{~g}$ para $10 \mathrm{~L}$ de água, sendo transplantadas, em seguida, para vasos de $5 \mathrm{~L}$. As mudas selecionadas apresentavam diâ- 
metro de coroa superior a $8 \mathrm{~mm}$, considerado de ótimo padrão (Ronque, 1998).

No preparo dos vasos foram utilizados $50 \%$ de substrato comercial Plantmax ${ }^{\circledR}$ e $50 \%$ de solo de área não cultivada, classificado como Latossolo Bruno distroférrico típico de textura argilosa (EMBRAPA, 2006). Nesta mistura, foi adicionado o adubo formulado NPK 4-14-8, na proporção de $1 \mathrm{~kg}$ de adubo para $50 \mathrm{~kg}$ de mistura. Na adubação de cobertura, foram aplicados, em cada vaso, $5 \mathrm{~g}$ do formulado NPK 20-00-20, a cada 30 dias, iniciando-se 30 dias após o transplante, seguindo-se as recomendações da cultura na região Centro-Sul do Paraná (Ronque, 1998). No início do florescimento, foram aplicados, via foliar, ácido bórico e sulfato de zinco, na concentração de 1 e $2 \%$, respectivamente. No estádio de produção de frutos, foi pulverizado cloreto de cálcio a $0,4 \%$, a cada 15 dias.

O controle das plantas daninhas foi realizado, manualmente, a cada 15 dias. A irrigação foi realizada por gotejamento, utilizando-se tubos gotejadores de polietileno flexível, espaçados de $0,30 \mathrm{~m}$, sendo o fluxo de água direcionado no centro de cada vaso. O controle de pulgões e ácaros foi realizado com pulverizações mensais de abamectin $(6 \mathrm{ml} / 10 \mathrm{~L})$ e o controle de doenças fúngicas foi realizado, aplicando-se, de forma alternada, Iprodione (150ml/100L) e Tebuconazole (750g/ha), a cada 15 dias.

Apesar de os estolões serem caracteres passíveis de avaliação para estudo de divergência genética, optou-se por sua remoção, em todas os cultivares, logo após a emissão, pois seriam avaliados em detrimento da avaliação de frutos, que são caracteres mais importantes no estudo em questão.

O plantio foi realizado em maio de 2009, iniciando-se a colheita 60 dias após, sendo todas as flores, produzidas até esta data, arrancadas, priorizando-se o desenvolvimento vegetativo da planta. Para a avaliação da produção, os frutos foram colhidos a cada dois dias, durante 120 dias, sendo colhidos os que apresentavam mais de 3/ 4 da superfície com coloração vermelha.

Foram avaliados 29 caracteres morfoagronômicos, baseando-se em escalas de nota adaptadas de SNPC (2009) e Faedi et al. (2009) (Tabela 1). As avaliações foram divididas em duas fases: $1^{\text {a }}$ florada, aos 60 dias após o plantio, sendo essas avaliações realizadas diretamente nos vasos, sob estufa; $2^{a}$ florada, aos 80 dias após o plantio, sendo tais avaliações realizadas em laboratório, utilizando-se frutos de cinco colheitas, congelados a $-20^{\circ} \mathrm{C}$ e, posteriormente, analisados. De cada repetição, foram avaliados três frutos por colheita, totalizando 15 frutos por repetição.

As avaliações dos caracteres morfoagronômicas foram realizadas de acordo com os seguintes procedimentos: 1) número total de frutos: contados todos os frutos colhidos, 2) peso total de frutos ( $\mathrm{g})$ : pesados todos os frutos, $\log$ o após a colheita, utilizando-se balança com precisão de duas casas decimais, 3) peso médio de fruto (g): obtido pela divisão do peso total de frutos pelo número total de frutos, 4) densidade da planta: utilizada escala baseada no número de trifólios, 5) número médio de trifólios por planta: contados os trifólios de todas as plantas da repetição, 6) tamanho das folhas $(\mathrm{cm})$ : medido em dez folíolos por vaso, com auxílio de um paquímetro digital, com precisão de duas casas decimais, 7) época de floração: utilizada escala determinada conforme a época do início da coleta de frutos, com valores variando de 1 (muito precoce) a 9 (muito tardio), 8) cor e brilho da superfície adaxial da folha: utilizando-se os trifólios completamente expandidos, atribuindo-se a nota ao conjunto de trifólios, 9) forma da seção transversal da folha: analisada visualmente, considerando-se a forma do conjunto de trifólios, sendo realizada ao término da tarde, sob temperatura amena $\left(18 \pm 2^{\circ} \mathrm{C}\right)$, evitando-se estresse por temperatura que poderia influenciar a forma das folhas, 10) relação comprimento /largura: analisada visualmente a forma da base e forma do recorte do folíolo terminal, utilizando-se três folíolos completamente expandidos por vaso, 11) pigmentação antociânica da estípula: analisada visualmente, diretamente na planta, 12) posição da inflorescência na folhagem: foi considerado se a inflorescência estava no nível ou fora do dossel foliar, 13) tamanho do cálice em relação à corola: analisado visualmente, observando-se, pelo plano superior, as flores com a corola completamente aberta, sendo atribuída nota 1, quando o cálice não é visível, 2, quando é visível apenas a ponta da sépala, e 3, quando todas as sépalas são visíveis, 14) tamanho da flor: foram amostradas cinco flores primárias de cada repetição, classificando- as em pequena, média e grande, 15) relação comprimento/largura da pétala: foram retiradas as pétalas das flores da análise anterior, distribuindo-as nos seus respectivos grupos, 16) tamanho do fruto em relação ao cálice: utilizaram-se apenas frutos maduros, não deformados e no tamanho padrão do cultivar, 17) remoção do fruto do cálice: no momento da colheita dos frutos, foi verificada a dificuldade de destacá-los do cálice, sendo, a amostragem, de cinco frutos por vaso, 18) inserção do fruto no cálice: as análises foram realizadas logo após a remoção dos frutos, removendo-se completamente o cálice e observando-se o formato da base do fruto, onde se dá a inserção. No caso do cálice incluso, a base fica levemente deprimida, dando ao fruto o formato de coração, 19) cor e brilho dos frutos: as avaliações foram realizadas de dia, com boa iluminação, em cinco frutos por vaso, 20) formato mais frequente de frutos: os frutos foram distribuídos em 
nove classes, sendo atribuída uma única nota ao formato mais frequente encontrado, 21) tamanho e zona sem aquênios nos frutos: a classificação foi realizada conforme comparação direta entre os frutos dos $11 \mathrm{cul-}$ tivares, 22) implantação e cor dos aquênios: análise re- alizada com o auxílio de lupa (20x) e 23) cavidade central, regularidade e distribuição da cor vermelha na polpa dos frutos: todos os frutos foram partidos ao meio, com o auxílio de uma lâmina, sendo os frutos avaliados na própria matriz.

Tabela 1. Caracteres morfoagronômicas analisados nos 11 cultivares de morangueiro, suas respectivas escalas de nota e época de avaliação

\begin{tabular}{|c|c|c|}
\hline Caracteres & Escalas de nota & poca deAvaliação \\
\hline \multicolumn{3}{|c|}{ Planta } \\
\hline Número e peso total de frutos & Caráteres Quantitativos & $1^{\mathrm{a}}$ e $2^{\mathrm{a}}$ Florada \\
\hline Densidade & 3-fraca; 5-média; 7-forte & $1^{\mathrm{a}}$ Florada \\
\hline Vigor & 3-fraca; 5-média; 7-forte & $1^{\text {a }}$ Florada \\
\hline Época de floração & $\begin{array}{l}\text { 1- muito precoce; } 3 \text { - precoce; 5- média; } \\
\text { 7- tardia; 9- muito tardia }\end{array}$ & $1^{\mathrm{a}}$ Florada \\
\hline \multicolumn{3}{|c|}{ Folha } \\
\hline Cor & 1- verde- clara; 3 -verde- média; 5- verde- escura; & $1^{\mathrm{a}}$ Florada \\
\hline Brilho & 3-fraca; 5-média; 7-forte & $1^{\text {a }}$ Florada \\
\hline Forma da secção transversal & 1- côncava; 2- plana; 3 - convexa & $1^{\mathrm{a}}$ Florada \\
\hline Relação comprimento/largura do & 1- mais larga que comprida; 2 - tão comprida & $1^{\mathrm{a}}$ Florada \\
\hline folíolo terminal & como larga; 3 - mais comprida do que larga & \\
\hline Forma da base do folíolo terminal & 1- acuneada; 2 - obtusa; 3 - arredondada & $1^{\mathrm{a}}$ Florada \\
\hline Forma do recorte do folíolo terminal & 1- serrilhada; 2 - crenada & $1^{\mathrm{a}}$ Florada \\
\hline Pigmentação antociânica da estípula & 1- ausente ou fraca; 2 - média; 3 - forte & $1^{\mathrm{a}}$ Florada \\
\hline \multicolumn{3}{|c|}{ Flores } \\
\hline Posição da inflorescência na folhagem & 1- no nível do dossel foliar; 2- fora do dossel foliar & $1^{\mathrm{a}}$ Florada \\
\hline Tamanho do cálice/corola & 1- menor; 2- do mesmo tamanho; 3- maior & $1^{\mathrm{a}}$ Florada \\
\hline Tamanho & 3-pequena; 5-média; 7-grande & $1^{\mathrm{a}}$ Florada \\
\hline Relação comprimento/largura da pétala & $\begin{array}{l}\text { 1- mais larga que comprida; } 2 \text { - tão comprida como larga; } \\
\text { 3- mais comprida do que larga }\end{array}$ & $1^{\mathrm{a}}$ Florada \\
\hline \multicolumn{3}{|c|}{ Fruto } \\
\hline Peso médio & Caráter Quantitativo & $1^{\mathrm{a}}$ e $2^{\mathrm{a}}$ Florada \\
\hline Tamanho em relação ao cálice & 1- muito menor; 2- menor; 3-igual; 4- maior; 5- muito maior & $1^{\mathrm{a}}$ Florada \\
\hline Remoção do cálice & 1- muito fraca; 2- fraca; 3- média; 4- forte; 5- muito forte & $1^{\mathrm{a}}$ Florada \\
\hline Inserção no cálice & 1- incluso; 2- plano; 3- saliente & $1^{\text {a }}$ Florada \\
\hline Cor & 1- vermelho- alaranjada; 2- vermelha; 3- vermelho- escuro; & $1^{\mathrm{a}}$ Florada \\
\hline Brilho & 3- fraco; 5- médio; 7-forte & $1^{\text {a }}$ Florada \\
\hline Formato mais frequente & $\begin{array}{l}\text { 1- reniforme; } 2 \text { - achatado; 3- globoso; 4- cônico; 5- bicônico; } \\
\text { 6- ovoide; 7- quase cilíndrico; } 8 \text { - cuneiforme; } 9 \text { - cordiforme }\end{array}$ & $2^{\mathrm{a}}$ Florada \\
\hline Tamanho & 1- muito pequeno; 3- pequeno; 5- médio; 7-grande; 9- muito grande & $2^{\mathrm{a}}$ Florada \\
\hline Zona sem Aquênios & 3-pequena; 5-média; 7-grande & $2^{\mathrm{a}}$ Florada \\
\hline Implantação dos aquênios & 1 - inclusos; 2 - emergentes; 3 - salientes & $2^{\mathrm{a}}$ Florada \\
\hline Cor dos Aquênios & 1- amarela; 2-verde; 3 - vermelha & $2^{\mathrm{a}}$ Florada \\
\hline Cavidade central & 1 - ausente; 2 - pequena; 3 -grande & $2^{\mathrm{a}}$ Florada \\
\hline Cor vermelha na polpa & $\begin{array}{l}\text { 1- apenas na margem; 2- na margem em direção ao centro; } \\
\text { 3- uniforme em toda a polpa }\end{array}$ & $2^{\mathrm{a}}$ Florada \\
\hline Regularidade da cor da polpa & 1- não uniforme; 2- quase uniforme; 3 - uniforme & $2^{\mathrm{a}}$ Florada \\
\hline
\end{tabular}

Adaptado de SNPC (2009).

Rev. Ceres, Viçosa, v. 58, n.3, p. 323-329, mai/jun, 2011 
Os dados morfoagronômicos foram submetidos à análise de variância, sendo eliminados os caracteres para os quais o efeito de tratamento foi não significativo $(\mathrm{p}<0,05)$. Inicialmente, foram obtidas duas matrizes de similaridade, uma com dados qualitativos e outra com dados quantitativos. Os dados qualitativos (multicategóricos) foram submetidos à análise multivariada, obtendo-se a matriz de similaridade genética, calculada com base no coeficiente de Jaccard. Para os dados quantitativos, utilizou-se, como medida de similaridade, a distância generalizada de Mahalanobis $\left(\mathrm{D}^{2}\right)$, com auxílio do aplicativo computacional GENES (Cruz, 2006). As matrizes foram padronizadas, dividindo-se o valor de cada elemento pelo desvio padrão da respectiva matriz, com a finalidade de reduzir a amplitude de variação em cada uma delas. A partir das novas matrizes de similaridade, formada com os valores padronizados, foi obtida uma matriz conjunta, cujos elementos foram dados pelas médias das distâncias padronizadas, obtidas a partir de cada conjunto de dados. A matriz conjunta de similaridade foi utilizada para a formação do dendrograma, tendo como princípio o método de agrupamento de médias aritméticas não ponderadas (UPGMA).

\section{RESULTADOS E DISCUSSÃO}

Dentre os 29 caracteres morfoagronômicos avaliados, para oito deles (produção de frutos, peso médio de frutos, vigor, brilho da folha, tamanho da flor, relação comprimento/ largura da pétala, zona sem aquênios no fruto e regularidade da cor da polpa) o efeito de tratamento foi não significativo, pelo teste $\mathrm{F}(\mathrm{p}<0,05)$, indicando que não existe variabilidade para essas características entre os cultivares estudados; por isso esses caracteres não foram utilizados na análise de divergência genética.

A similaridade média detectada pelos caracteres morfoagronômicos foi de 38\%, variando de 19\% (Aromas e Camino Real) a 62\% (Camino Real e Camarosa; Aromas e Sweet Charlie) (Tabela 2). Conti et al. (2002) avaliaram doze caracteres morfoagronômicos em cinco cultivares de morangueiro (Campinas, Dover, Guarani, Princesa Isa- bel e AGF 080), e observaram 45\% de similaridade, valores superiores aos observados neste estudo.

A genealogia dos cultivares não apresentou relação direta com os resultados de similaridade genética. Os cultivares Aromas e Diamante, que advêm do mesmo cruzamento (Cal. 87.112-6’ x ‘Cal. 88.270-1), porém, selecionadas em anos diferentes, apresentaram 52\% de similaridade genética, valores considerados baixos, por possuírem os dois genitores em comum. Outros exemplos de baixa similaridade, envolvendo cultivares aparentados, são: Dover e Oso Grande (24\%), Dover e Tudla (24\%), Dover e Sweet Charlie (24\%), Dover e Camarosa (29\%) e Tudla e Oso Grande (33\%).

O dendrograma formado com base nas similaridades genéticas dividiu os cultivares em três grupos, considerando-se, como ponto de corte, a similaridade média de todas os cultivares (38\%) (Figura 1). O país de origem dos cultivares não foi fator decisivo na formação dos grupos, pois o grupo I possui cultivares de três países (Estados Unidos, Brasil e Japão) e, o grupo II, de dois países (Estados Unidos e Espanha). Isso ocorre por causa do material genético utilizado pelos programas de melhoramento, pois muitos usam cultivares provenientes dos programas de melhoramento norte-americanos. A título de exemplo, tomase o cultivar Campinas, desenvolvido no Brasil e com genitores provenientes dos Estados Unidos (Tahoe e Donner) (Camargo \& Passos, 1993). Comparando-se os dendrogramas com a genealogia, observa-se coerência no grupo I (Aromas e Diamante; Sweet Charlie e Campinas) e no grupo II (Camarosa e Tudla). Contudo, a maioria dos cultivares aparentados não se agruparam coerentemente com a genealogia. A formação de grupos pode representar valiosa informação na escolha de genitores, dentro dos programas de melhoramento, pois as novas populações híbridas a serem estabelecidas devem ser baseadas na magnitude de suas distâncias e no potencial "per se" dos genitores (Bertan et al., 2006).

A similaridade obtida entre cultivares possibilita a identificação de genitores adequados à obtenção de cruza-

Tabela 2. Matriz de similaridade genética entre cultivares de morangueiro com base em dados de caracteres morfoagronômicos

\begin{tabular}{|c|c|c|c|c|c|c|c|c|c|c|}
\hline & Aromas & $\begin{array}{c}\text { Camino } \\
\text { Real }\end{array}$ & Camarosa & Campinas & Diamante & Dover & $\begin{array}{c}\text { Oso } \\
\text { Grande }\end{array}$ & $\begin{array}{c}\text { Sweet } \\
\text { Charlie }\end{array}$ & Toyonoka & Tudla \\
\hline Camino Real & 0,19 & & & & & & & & & \\
\hline Camarosa & 0,52 & 0,62 & & & & & & & & \\
\hline Campinas & 0,33 & 0,24 & 0,24 & & & & & & & \\
\hline Diamante & 0,52 & 0,29 & 0,48 & 0,57 & & & & & & \\
\hline Dover & 0,38 & 0,43 & 0,29 & 0,48 & 0,24 & & & & & \\
\hline Oso Grande & 0,38 & 0,33 & 0,38 & 0,38 & 0,43 & 0,24 & & & & \\
\hline Sweet Charlie & 0,62 & 0,24 & 0,52 & 0,48 & 0,57 & 0,24 & 0,48 & & & \\
\hline Toyonoka & 0,29 & 0,29 & 0,33 & 0,52 & 0,48 & 0,43 & 0,29 & 0,29 & & \\
\hline Tudla & 0,48 & 0,29 & 0,48 & 0,38 & 0,24 & 0,24 & 0,33 & 0,38 & 0,33 & \\
\hline Ventana & 0,57 & 0,29 & 0,52 & 0,48 & 0,57 & 0,24 & 0,57 & 0,57 & 0,29 & 0,33 \\
\hline
\end{tabular}




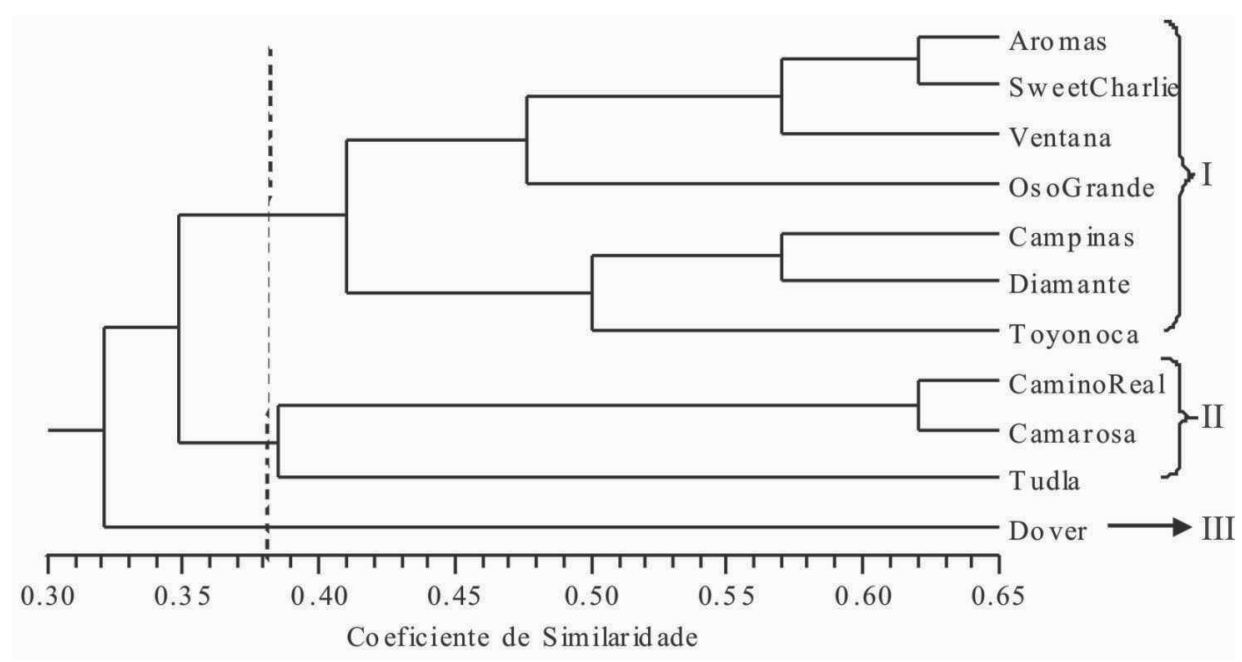

Figura 1. Dendrograma de similaridade genética entre 11 cultivares de morangueiro, obtido a partir de caracteres morfoagronômicos, utilizando o método de agrupamento UPGMA. A linha pontilhada indica o ponto de corte com base na similaridade média calculada de $38 \%$.

mentos, com maior efeito heterótico, aumentando a possibilidade de obtenção de indivíduos superiores (Cruz \& Carneiro, 2003). Nesse sentido, com base na matriz de similaridade, pode-se inferir que o cruzamento mais promissor é entre os cultivares Camarosa e Campinas, que apresentam baixa similaridade (24\%). Como 13 dos 21 caracteres avaliados foram relacionados diretamente com o fruto, esse cruzamento proporcionará descendentes divergentes para a qualidade do fruto, o que torna esse cruzamento ainda mais promissor, pois a qualidade do fruto é uma das principais características buscadas pelos programas de melhoramento da cultura. Outro fator, a ser levado em consideração, é o elevado potencial produtivo do cultivar Camarosa, na região, com produtividade superior a 55 t ha $^{-1}$ (Resende et al., 2010).

Considerando-se a similaridade média de cada cultivar, em relação aos outros 10, o cultivar Tudla apresentou a menor similaridade média (33\%) e, o cultivar Ventana, a maior (45\%). Desta forma, o cultivar Tudla pode ser útil em programas de melhoramento genético, por sua baixa similaridade geral, possuindo diversos caracteres divergentes em relação aos outros cultivares, tais como, densidade de folhas, tamanho e formato de frutos.

Informações relativas ao comportamento de caracteres morfoagronômicos, em regiões nas quais se pretende implantar um programa de melhoramento, são fundamentais para auxiliar o melhorista na escolha dos melhores cruzamentos, possibilitando a concentração de esforços nas combinações mais promissoras. Dessa forma, estes resultados são úteis para o entendimento da base genética dos cultivares de morango e servem de subsídios para futura implantação de um programa de melhoramento, visando ao desenvolvimento de cultivares adaptados à região Centro-Sul do Paraná, assim como para outras regiões brasileiras.

\section{CONCLUSÕES}

Os valores de similaridade entre os cultivares e o agrupamento destes no dendrograma não apresentaram relação direta com suas origens e genealogias.

O cultivar Tudla é a mais divergente com relação aos demais cultivares estudados, sendo recomendada para aumentar a base genética em programas de melhoramento genético.

O cruzamento mais promissor com base nos caracteres morfoagronômicos é entre os cultivares Camarosa e Campinas.

\section{REFERÊNCIAS}

Bertan I, Carvalho FIF, Oliveira AC, Silva AG, Benin G, Vieira EA, Silva GO, Hartwig I, Valério IP \& Finatto T (2006) Dissimilaridade genética entre genótipos de trigo avaliados em cultivo hidropônico sob estresse por alumínio. Bragantia, 65:5563.

Camargo LS \& Passos FA (1993) Morango. In: Furlani AMC, Viégas GP (Eds) O melhoramento de plantas no Instituto Agronômico. Campinas, Instituto Agronômico, p.411-432.

Chahidi B, El-otmani M, Jacquemond C, Tijane M. El-mousadik A, Srairi I \& Luro F (2008) Utilisation de caractères morphologiques, physiologiques et de marqueurs moléculaires pour l'évaluation de la diversité génétique de trois cultivars de clémentinier. Comptes Rendus Biologies, 331:1-12.

Conti JH, Minami K \& Tavares FCA (2002) Comparação de caracteres morfológicos e agronômicos com moleculares em morangueiros cultivados no Brasil. Horticultura Brasileira, 20:419-423.

Cruz CD \& Carneiro PCS (2003) Modelos biométricos aplicados ao melhoramento genético. Viçosa, Editora UFV. 585p.

Cruz CD (2006) Programa GENES: análise multivariada e simulação. Viçosa, Imprensa Universitária. 285p.

Embrapa. Centro nacional de pesquisa de solos (2006) Sistema brasileiro de classificação de solos. Rio de Janeiro, Embrapa. $306 \mathrm{p}$. 
Faedi W, Baruzzi G, Lovati F, Sbrighi P \& Lucchi P (2009) Monografia di cultivar di fragola. Roma, Istituto Sperimentale per la Frutticoltura Roma. v.2, 240p.

Fufa H, Baenziger PS, Beecher BS, Dweikat I, Graybosch RA \& Eskridge KM (2005) Comparison of phenotypic and molecular marker-based classifications of hard red winter wheat cultivars. Euphytica, 145:133-146.

Gichuki ST, Berenyl M, Zhang D, Hermann M, Schmidt J, Glossol J \& Burg K (2003) Genetic diversity in sweet potato (Ipomoed atatas) in relationship to geographic source as assessed with RAPD markers. Genetic resources and crop evolution, 5:429_ 437

Klocke E, Langbehn J, Grewe C \& Pank F (2002) DNA fingerprinting by RAPD on Origanum majorana. Journal of Herbs, Spices \& Medicinal Plants, 9:171-176.
Milach SCK (1998) Marcadores moleculares em plantas. Porto Alegre, UFRGS. 141p.

Resende JTV, Morales RGF, Faria MV, Rissini ALL, Camargo LKP \& Camargo CK (2010). Produtividade e teor de sólidos solúveis de frutos de cultivares de morangueiro em ambiente protegido. Horticultura Brasileira, 28:185-189.

Ronque VER (1998) A cultura do morangueiro. Curitiba, EMATERPR, 206p.

SNPC (2009) Serviço nacional de proteção de cultivares. Disponível em: <http://www.agricultura.gov.br/arq_editor/file/vegetal/ $\begin{array}{lllllllllllllllllllll}\mathrm{R} & \mathrm{e} & \mathrm{g} & \mathrm{i} & \mathrm{s} & \mathrm{t} & \mathrm{r} & \mathrm{o} & \mathrm{A} & \mathrm{u} & \mathrm{t} & \mathrm{o} & \mathrm{r} & \mathrm{i} & \mathrm{z} & \mathrm{a} & \mathrm{c} & \mathrm{o} & \mathrm{e} & \mathrm{s} & \text { / }\end{array}$ Formularios \%20Prote\%C3\% A7\% C3\% A3o\%20Cultivares/ MORANGO_US.doc>. Acessado em: 06 de abril de 2011.

Thomaz EL \& Vestena LR (2003) Aspectos climáticos de Guarapuava, PR. Guarapuava, UNICENTRO. 106p. 